\title{
Excess Volumes of Ternary Mixtures Containing p-Chlorotoluene and Octane with 1-Alkanols at 303.15 K
}

\author{
Kasibhatta S. Kumar and Puligundla R. Naidu* \\ Department of Chemistry, S. V. University College, Tirupati 517502, India \\ William E. Acree, Jr. \\ Department of Chemistry, University of North Texas, Denton, Texas 76203-5068
}

\begin{abstract}
New excess volume data for three ternary mixtures containing $p$-chlorotoluene $(1)+1$-pentanol (2) + octane (3), p-chlorotoluene (1) + 1-hexanol (2) + octane (3), and p-chlorotoluene (1) + 1-heptanol (2) + octane (3) have been measured at $303.15 \mathrm{~K}$. The data were compared with those predicted by a semiempirical relation which has been recently proposed and the Redlich-Kister relation.
\end{abstract}

\section{Introduction}

Thermodynamic and physical properties of liquid mixtures are used in design calculations involving chemical separation, fluid flow, and heat transfer. Thermodynamic properties for binary systems are extensively reported in the literature, while those reported for ternary systems are scarce. Further, data for properties of multicomponent mixtures are not reported in the literature. The measurement of thermodynamic properties of ternary and multicomponent mixtures becomes difficult as these involve sophisticated instruments and the complex problems associated with the operation of the units. Hence, efforts $(1-7)$ have been made over the years to formulate empirical and semiempirical equations which permit prediction of thermodynamic properties of ternary and multicomponent mixtures from the experimental data of the constituent binaries. Most of these equations take into account mainly pairwise interactions. However, Hwang et al. (8) have recently developed a semiempirical equation that provides for contribution from both two-body and threebody interactions. It has been shown that the expression satisfactorily predicts ternary free energies of several aqueous organic systems.

Recently Acree and Naidu (9) extended the relation to excess volumes of six ternary mixtures (10-15) and noted that the equation gives a satisfactory estimate of the excess property. We report here new experimental excess volume data for three ternary mixtures, and the data are compared with those predicted by the new semiempirical expression (8) and also with the Redlich-Kister relation (1).

Table I. Densities ( $\rho$ ) of Pure Components at 303.15 K

\begin{tabular}{lcc}
\hline & \multicolumn{2}{c}{$\rho /\left(\mathrm{g} \mathrm{cm}^{-3}\right)$} \\
\cline { 2 - 3 } component & lit. $(18,19)$ & present study \\
\hline p-chlorotoluene & $1.06510^{a}$ & $1.06514^{a}$ \\
1-pentanol & 0.80764 & 0.80762 \\
1-hexanol & 0.81201 & 0.81205 \\
1-heptanol & 0.81574 & 0.81572 \\
octane & 0.69450 & 0.69445 \\
a At $298.15 \mathrm{~K}$. & &
\end{tabular}

\section{Experimental Procedure}

All the chemicals used were of analytical grade. 1-Pentanol (Fluka), 1-hexanol (BDH), 1-heptanol (S.D. Fine Chemicals),

* To whom correspondence should be addressed.
Table II. Binary Parameters Obtained by the Method of Least Squares Using the Redlich-Kister Equation (1)

\begin{tabular}{lrrr}
\hline \multicolumn{1}{c}{ system } & \multicolumn{1}{c}{$a_{0}$} & \multicolumn{1}{c}{$a_{1}$} & \multicolumn{1}{c}{$a_{2}$} \\
\hline$p$-chlorotoluene (1) + 1-pentanol (2) + & & & \\
$\quad$ octane (3) & & & \\
$\begin{array}{l}p \text {-chlorotoluene (1) + 1-pentanol (2) } \\
p \text {-chlorotoluene (1) + octane (3) }\end{array}$ & -0.0512 & 0.5996 & -0.4199 \\
$\begin{array}{l}\text { 1-pentanol (2) + octane (3) } \\
p \text {-chlorotoluene (1) + 1-hexanol (2) + }\end{array}$ & 0.8099 & -0.0882 & -0.5437 \\
$\quad$ & & & \\
$\quad$ octane (3) & & & \\
p-chlorotoluene (1) + 1-hexanol (2) & -0.1956 & 0.6900 & 0.4253 \\
$\begin{array}{l}p \text {-chlorotoluene (1) + octane (3) } \\
\text { 1-hexanol (2) + octane (3) }\end{array}$ & -0.8099 & -0.0882 & -0.5437 \\
$p$-chlorotoluene (1) + 1-heptanol (2) + & 0.4201 & -0.9344 & 0.3454 \\
$\quad$ octane (3) & & & \\
$\begin{array}{l}p \text {-chlorotoluene (1) + 1-heptanol (2) } \\
p \text {-chlorotoluene (1) + octane (3) }\end{array}$ & -0.1276 & 0.7385 & -0.1088 \\
1-heptanol (2) + octane (3) & -0.8099 & -0.0882 & -0.5437 \\
& 0.0750 & -0.6990 & 0.1390
\end{tabular}

Table III. Binary Parameters Obtained by Using the Hwang et al. Equation (4)

\begin{tabular}{|c|c|c|c|}
\hline system & $V_{0}^{(i)}$ & $V_{1}^{(i j)}$ & $V_{2}^{(i j)}$ \\
\hline \multicolumn{4}{|l|}{$\begin{array}{l}p \text {-chlorotoluene (1) + 1-pentanol (2) + } \\
\text { octane (3) }\end{array}$} \\
\hline$p$-chlorotoluene (1) + 1-pentanol (2) & 0.1139 & -0.0063 & -1.3210 \\
\hline & -0.6274 & -0.8273 & -0.6172 \\
\hline $\begin{array}{l}\text { 1-pentanol (2) + octane (3) } \\
\text { p-chlorotoluene }(1)+1 \text {-hexanol (2) + } \\
\text { octane (3) }\end{array}$ & 0.78 & -0.5802 & 1.4706 \\
\hline lene $(1)+1$-hexanol (2) & -0.3372 & 1.3874 & -0.2542 \\
\hline & & -0.8 & \\
\hline $\begin{array}{l}\text { 1-hexanol }(2)+\text { octane }(3) \\
\text { p-chlorotoluene }(1)+1 \text {-heptanol }(2)+ \\
\text { octane }(3)\end{array}$ & & -0.6510 & \\
\hline & & & \\
\hline & & & \\
\hline 1-heptanol (2) + octane (3) & 0.0286 & -0.6478 & 1.0176 \\
\hline
\end{tabular}

and octane (S. D. Fine Chemicals) were purified by the methods described by Riddick and Bunger (16). $p$-Chlorotoluene (Fluka) was purified by the method described by Vogel (17). 1-Pentanol (Fluka) and 1-hexanol (BDH) were dried over Drierite and fractionally distilled. 1-Heptanol (S.D. Fine Chemicals) was fractionated. Octane (S.D. Fine Chemicals) was purified by drying it over sodium wire for 1 day. It was then refluxed for $4 \mathrm{~h}$ and finally fractionally distilled. $p$-Chlorotoluene (Fluka) was washed successively with an aqueous $10 \%$ solution of sodium hydroxide, concentrated sulfuric acid, and water. It was dried with anhydrous calcium chloride, decanted, and distilled. The purities of the samples 
Table IV. Experimental and Predicted Excess Molar Volumes for the Ternary Mixtures p-Chlorotoluene (1) + 1-Alkanol (2) + Octane (3) at $303.15 \mathrm{~K}$

\begin{tabular}{|c|c|c|c|c|c|c|}
\hline \multirow[b]{2}{*}{$x_{1}$} & \multirow[b]{2}{*}{$x_{2}$} & \multicolumn{3}{|c|}{$V(123)$} & \multicolumn{2}{|c|}{$\Delta V^{\mathbb{E}(123)}$} \\
\hline & & $\exp$ & Redlich-Kister & Hwang et al. & Redlich-Kister ${ }^{a}$ & Hwang et al. ${ }^{b}$ \\
\hline \multicolumn{7}{|c|}{ p-Chlorotoluene (1) + 1-Pentanol (2) + Octane (3) } \\
\hline 0.2442 & 0.1359 & 0.069 & -0.012 & -0.020 & 0.081 & 0.089 \\
\hline 0.1189 & 0.2463 & 0.159 & 0.127 & 0.124 & 0.032 & 0.035 \\
\hline 0.2252 & 0.3445 & 0.075 & 0.055 & 0.069 & 0.020 & 0.006 \\
\hline 0.1718 & 0.3813 & 0.092 & 0.086 & 0.097 & 0.006 & -0.005 \\
\hline 0.2389 & 0.3944 & 0.014 & 0.040 & 0.063 & -0.026 & -0.049 \\
\hline 0.2089 & 0.4895 & -0.052 & 0.033 & 0.066 & -0.085 & -0.014 \\
\hline 0.1666 & 0.5524 & -0.044 & 0.037 & 0.071 & -0.081 & -0.115 \\
\hline 0.1526 & 0.6713 & -0.111 & -0.006 & 0.026 & -0.105 & -0.137 \\
\hline 0.1345 & 0.7548 & -0.105 & -0.032 & -0.011 & -0.073 & -0.094 \\
\hline 0.1012 & 0.8478 & -0.079 & -0.049 & -0.044 & -0.030 & -0.035 \\
\hline \multicolumn{7}{|c|}{$p$-Chlorotoluene (1) + 1-Hexanol (2) + Octane (3) } \\
\hline 0.1620 & 0.1873 & 0.007 & -0.091 & -0.005 & 0.098 & 0.002 \\
\hline 0.2067 & 0.1664 & 0.020 & -0.110 & -0.041 & 0.130 & 0.061 \\
\hline 0.1289 & 0.2586 & 0.024 & -0.050 & 0.031 & 0.074 & -0.007 \\
\hline 0.1776 & 0.3047 & 0.039 & -0.041 & -0.005 & 0.080 & 0.044 \\
\hline 0.1332 & 0.3438 & 0.034 & -0.010 & 0.025 & 0.044 & 0.009 \\
\hline 0.1523 & 0.4493 & 0.016 & 0.029 & -0.003 & -0.013 & 0.013 \\
\hline 0.1970 & 0.5883 & -0.149 & 0.031 & -0.047 & -0.180 & -0.102 \\
\hline 0.1437 & 0.6619 & -0.060 & 0.061 & -0.040 & -0.121 & -0.020 \\
\hline 0.1339 & 0.7192 & -0.044 & 0.053 & -0.046 & -0.097 & 0.002 \\
\hline 0.1226 & 0.7408 & -0.036 & 0.056 & -0.046 & -0.092 & 0.010 \\
\hline \multicolumn{7}{|c|}{$p$-Chlorotoluene (1) + 1-Heptanol (2) + Octane (3) } \\
\hline 0.2054 & 0.1289 & -0.075 & -0.081 & -0.086 & 0.006 & 0.011 \\
\hline 0.2026 & 0.2450 & -0.036 & -0.062 & -0.062 & 0.026 & 0.026 \\
\hline 0.1953 & 0.2771 & -0.024 & -0.059 & -0.056 & 0.035 & 0.032 \\
\hline 0.1259 & 0.3897 & -0.012 & -0.041 & -0.030 & 0.029 & 0.018 \\
\hline 0.2014 & 0.4773 & -0.036 & -0.090 & -0.062 & 0.054 & 0.026 \\
\hline 0.1686 & 0.4884 & -0.037 & -0.082 & -0.060 & 0.045 & 0.023 \\
\hline 0.1940 & 0.5440 & -0.058 & -0.099 & -0.015 & 0.041 & -0.043 \\
\hline 0.2325 & 0.6123 & -0.085 & -0.110 & -0.079 & 0.025 & -0.006 \\
\hline 0.1104 & 0.7716 & -0.086 & -0.096 & -0.148 & 0.010 & 0.062 \\
\hline 0.1012 & 0.8109 & -0.082 & -0.091 & -0.080 & 0.009 & -0.002 \\
\hline
\end{tabular}

${ }^{a} \Delta V^{\mathbb{E}(123)}=V^{\mathbb{E}(123)}(\exp )-V^{\mathbb{E}(123)}\left(\right.$ Redlich-Kister). ${ }^{b} \Delta V^{\mathbb{E}(123)}=V^{\mathbb{E}(123)}(\exp )-V^{\mathbb{E}(123)}($ Hwang et al.).

were checked by comparing the measured densities of the components with those reported in the literature $(18,19)$. Densities of pure liquids were measured with a bicapillary pycnometer which offered an accuracy of $\pm 0.00002 \mathrm{~g} \mathrm{~cm}^{-3}$. The measured densities and the literature data are presented in Table $\mathrm{I}$.

Excess volumes for ternary systems were measured with a three-limbed dilatometer described by Naidu and Naidu (20). The mixing cell contains three limbs of different capacities connected through a W tube. Mercury was taken at the bottom of the bulbs of the dilatometer to separate the three components. One of the bulbs was fitted with a capillary (i.e. $1.0 \mathrm{~mm}$ ), and the other two bulbs were fitted with groundglass stoppers. Four dilatometers of the aforementioned types were used to cover the entire range of composition. All the measurements were made at constant temperature employing a thermostat that could be maintained to $\pm 0.01 \mathrm{~K}$. The measured $V^{E}$ values were accurate to $\pm 0.003 \mathrm{~cm}^{3} \mathrm{~mol}^{-1}$.

\section{Results and Discussion}

The dependence of $V^{\mathrm{E}}$ on composition may be expressed by an empirical equation proposed by Redlich-Kister (1) as follows:

$$
V^{\mathrm{E}}=x_{1} x_{2}\left[a_{0}+a_{1}\left(x_{1}-x_{2}\right)+a_{2}\left(x_{1}-x_{2}\right)^{2}\right]
$$

where $x_{1}$ and $x_{2}$ denote the mole fractions of components 1 and 2 and $a_{0}, a_{1}$, and $a_{2}$ are constants. The equation, when extended to a ternary mixture, takes the form

$V^{\mathrm{E}(123)}=x_{1} x_{2} x_{3}\left[a_{0}+a_{1} x_{1}\left(x_{2}-x_{3}\right)+a_{2} x_{1}{ }^{2}\left(x_{2}-x_{3}\right)^{2}\right]$
Hwang et al. (8) developed the relation

$$
A^{\mathrm{E}(12)}=G^{\mathrm{E}(12)}=x_{1} x_{2}\left[a_{0}+a_{1} x_{1}^{3}+a_{2} x_{2}^{3}\right]
$$

where $A^{\mathrm{E}(12)}=G^{\mathrm{E}(12)}$ represents an excess thermodynamic property. $x_{1}$ and $x_{2}$ denote the mole fractions of components 1 and 2. $a_{0}, a_{1}$, and $a_{2}$ are the constants for binary mixtures taking into account two-body and three-body interactions. Acree and Naidu (9) adopted the equation for excess volume in the following form:

$$
V^{\mathrm{E}(12)}=x_{1} x_{2}\left[a_{0}+a_{1} x_{1}{ }^{3}+a_{2} x_{2}{ }^{3}\right]
$$

They also extended the predictive approach to ternary $V^{\mathrm{E}}$ and employed the equation

$$
\begin{aligned}
& V^{E(123)}=x_{1} x_{2}\left(V_{0}^{(12)}+V_{1}^{(12)} x_{1}{ }^{3}+V_{2}^{(12)} x_{2}{ }^{3}\right)+ \\
& x_{1} x_{3}\left(V_{0}^{(13)}+V_{1}^{(13)} x_{1}{ }^{3}+V_{3}^{(13)} x_{3}{ }^{3}\right)+x_{2} x_{3}\left(V_{0}^{(23)}+\right. \\
& \left.V_{2}^{(23)} x_{2}{ }^{3}+V_{3}^{(23)} x_{3}{ }^{3}\right)
\end{aligned}
$$

to predict the ternary $V^{\mathrm{E}}$ data from the basis of constituent binaries. The predicted data were compared with experimental results of six ternary mixtures, and it was concluded that the new predictive expression gives a good estimate of ternary $V^{E}$

We analyze here new experimental $V^{E}$ data for three ternary mixtures in light of the aforementioned equation. Furthermore, the binary parameters for these ternary mixtures were collected from the literature (21-23) using the Redlich-Kister relation, and these are listed in Table II. The $V$ coefficients in eq 5 were computed from the smoothed binary experimental mole fraction $x_{1}=0.2,0.5$, and 0.8 data and are given in Table III. 
Experimental ternary excess volume data for three ternary systems are given in Table IV. Furthermore, the $V^{\mathrm{E}}$ data predicted by the equations proposed by Redlich-Kister and Hwang et al. are included in columns 4 and 5 of Table IV. The differences between experimental and predicted data are given in columns 6 and 7 of Table IV.

An examination of the results included in Table IV show that the Hwang et al. equation gives a rough estimate of $V^{E}$ in all three mixtures. However, the predictive capability of the relation is comparable to that of the Redlich-Kister relation.

\section{Literature Cited}

(1) Redlich, O.; Kister, A. T. Ind. Eng. Chem. 1948, 40, 345.

(2) Bertrand, G. L.; Acree, W. E., Jr.; Burchfield, T. E. J. Solution Chem. 1983, 12, 327.

(3) Acree, W. E., Jr.; Bertrand, G. L. J. Solution Chem. 1983, 12, 755

(4) McCargar, J.W.; Acree, W. E., Jr. Thermochim. Acta 1989, 149, 363.

(5) Tsao, C. C.; Smith, J. M. Applied Thermodynamics. Chem. Eng. Prog., Symp. Ser. 1953, No. 7, 107.

(6) Kohler, E. Monatsh. Chem. 1960, 91, 738.

(7) Jacob, K. T.; Fitzner, K. Thermochim. Acta 1977, 18, 197.

(8) Hwang, C. A.; Holste, J. C.; Hall, K. R.; Mansoori, G. A. Fluid Phase Equilib. 1991, 62, 173
(9) Acree, W. E., Jr.; Naidu, P. R. Phys. Chem. Liq., in press.

(10) Rastogi, R. P.; Nath, J.; Dass, S. S. J. Chem. Eng. Data 1977, 22, 249.

(11) Singh, P. R.; Sharma, V. K. Can. J. Chem. 1983, 61, 2321.

(12) Singh, P. R.; Sharma, S. P. J. Chem. Eng. Data 1985, 30, 477.

(13) Srinivasulu, U.; Naidu, P. R. Indian J. Technol. 1989, 27, 577.

(14) Naidu, G. R.; Naidu, P. R. J. Chem. Eng. Data 1982, $27,57$.

(15) Somoza, J. A.; Garlia, M.; Rey, C.; Rodriguez, J. R.; Villar, V. P. J. Chem. Thermodyn. 1984, 16, 1053.

(16) Riddick, J. A.; Bunger, W. B. Techniques of Chemistry, 3rd ed.; Wiley-Inserscience: New York, 1979.

(17) Vogel, A. I. A. Textbook of Practical Organic Chemistry, 4th ed.; Longman, ELBS: London, 1978.

(18) Timmermans, J. Physico-Chemical Constants of Pure Organic Compounds; Elsevier: New York, 1950.

(19) Kirk-Othmer. Encylopedia of Chemical Technology, 3rd ed.; Wiley-Interscience: New York, 1979; Vol. 5.

(20) Naidu, G. R.; Naidu, P. R. J. Chem. Eng. Data 1981, 26, 197.

(21) Sivakumar, K.; Naidu, P. R. J. Chem. Eng. Data, in press.

(22) Gupta, B. M. C.; Naidu, P. R.; Rao, M. V. P. J. Chem. Thermodyn. 1976, 8, 191.

(23) Sivakumar, K.; Naidu, P. R. Indian J. Technol. 1991, 29, 250.

Received for review August 10, 1992. Revised April 27, 1993. Accepted July 8, 1993.

- Abstract published in Advance ACS Abstracts, September 15, 1993. 